\title{
Measuring the Association of Overweight and Obesity with Human Disease and Other Factors in Bangladesh
}

\author{
Md. Roshidul Islam, Md. Anamul Haque \\ Department of Statistics, Begum Rokeya University, Rangpur, Bangladesh \\ Email: mroshid.brur@gmail.com, anamul.brur@gmail.com
}

How to cite this paper: Islam, M.R. and Haque, M.A. (2020) Measuring the Association of Overweight and Obesity with $\mathrm{Hu}$ man Disease and Other Factors in Bangladesh. Open Journal of Statistics, 10, 402-411. https://doi.org/10.4236/ojs.2020.103026

Received: April 4, 2020

Accepted: May 10, 2020

Published: May 13, 2020

Copyright $\odot 2020$ by author(s) and Scientific Research Publishing Inc. This work is licensed under the Creative Commons Attribution International License (CC BY 4.0).

http://creativecommons.org/licenses/by/4.0/

\section{(c) (i) Open Access}

\begin{abstract}
Overweight and obesity in people are epidemic in North America and internationally. In the United States, the number of overweight children and adolescents has doubled in the last two to three decades, and similar increasing rates are being observed worldwide, including developing countries as Bangladesh where an increase in Westernization of behavioral and dietary lifestyles is evident. Human diseases associated with overweight and obesity are similar in children as in the adult population. The main purpose of this study was to examine the association between overweight and obesity with human disease and other factors in Bangladesh. We have attempted to estimate the relationship between associated variables by using the Pearson Chi-Square test. It also showed how important an individual variable is by itself. The study also employed a statistical technique namely, logistic regression analysis which has been used to find out the association of overweight and obesity with human disease and other factors. We have seen that $16.96 \%$ people are overweight and 4.14\% people are obese, i.e. $21.1 \%$ people are overweight or obese in Bangladesh. From the logistic regression analysis technique among the independent variables type of place of residence, Highest educational level, Wealth index, Current marital status, Ever had vaccination, Had fever in last two weeks, Had cough in last two weeks, Short, rapid breaths, Problem in the chest or blocked or running nose have significant effect on dependent variable BMI classification.
\end{abstract}

\section{Keywords}

Body Mass Index, Overweight, Obesity, Human Disease, Logistic Regression

\section{Introduction}

A wide variety of personal behaviors affect an individual's health. In the aggre- 
gate, these behaviors affect the health of populations. The leading behaviors that have been singled out as especially damaging to the health of the Bangladeshi population are overweight and obesity. Awareness of the association of obesity with health problems is longstanding. During the past few decades, the prevalence of obesity has grown to epidemic proportions, and this condition is now known to be a major contributor to the global burden of disease. Obesity prevalence is still increasing rapidly, not only in industrialized countries but also in non-industrialized countries, particularly in those undergoing economic transition. Worldwide, around 250 million people are obese, and the World Health Organization (WHO) has estimated that in 2025, 300 million people will be obese [1]. Attitudes toward obesity differ across populations and, with economic changes, may change within populations over time. In industrialized countries, obesity is most common among those with low socio-economic status. The opposite is true in non-industrialized countries, where obesity is most often seen among individuals with high income and may be considered a status symbol. This effect may change as non-industrialized countries become more affluent and obesity is seen increasingly in those with low socio-economic status. Overweight and obesity are important determinants of human disease. The increasing prevalence of obesity contributes to a reduction in quality of life. Overweight and obesity in adulthood are associated with multiple co-morbidities; most notably type- 2 diabetes, cardiovascular disease, and a number of cancers. Dramatic rises in childhood obesity prevalence over the last 30 years have brought increasing attention to the potential long-term health consequences of childhood obesity. However, our understanding of the associations of childhood obesity with long-term health is incomplete. In particular, due to the tracking of adiposity from childhood into later life, it remains unclear whether childhood obesity has an effect on adult health that is independent of adult weight status. Previous reviews have examined the relationship between childhood obesity and morbidity in adulthood, but have not considered whether the effects of childhood adiposity are independent of adult overweight. The objective of this review was to systematically evaluate the current evidence on the contribution of childhood body mass index (BMI) to adult disease risk, independent of adult BMI. We paid particular attention to the methods used to assess these independent effects, and considered the strengths and limitations of these approaches.

\section{Objectives of the Study}

The main purposes of this study are to describe secular changes in overweight, obesity and the health status as well as disease of the Bangladeshi people. A logical statement of the objectives is most helpful to any scientific undertaking. Without this, it becomes complex in the context of reaching a decision and making inference. So in this research, our first step is to give clear statement of objectives of the study. The specific objectives of this study are as follows:

1) To determine the prevalence of overweight and obesity of people in Ban- 
gladesh.

2) To explore the present situation of different human diseases in Bangladesh.

3) To measure the association of overweight and obesity with human disease and other factors in Bangladesh.

\section{Source of Data}

For measuring the association of overweight and obesity with human disease and other factors in Bangladesh, we have mainly used the data of size 2730 individuals extracted using simple random sampling from the response of population record questionnaire of 2014 Bangladesh Demographic and Health Survey (BDHS) which contains a record of 43,772 individuals. The survey was conducted under the authority of the National Institute for Population Research and Training (NIPORT) of the Ministry of Health and Family Welfare [2]. The survey was implemented by Mitra and Associates, a Bangladeshi Research firm located in Dhaka. Macro International Inc., a private research firm located in Calverton Maryland, USA, provided technical assistance to the survey as part of its international Demographic and Health Surveys Program. The U.S Agency for International Development (USAID)/Bangladesh provided financial assistance.

\section{Variables}

Though there are numerous factors, we considered only a few selected variables in our study.

\subsection{Response Variable}

To measure the association of overweight and obesity with human disease and other factors in Bangladesh, we used Body Mass Index (BMI) as the response variable in this study. The dependent variable used in this analysis was found directly from the BDHS data set which is supported as a dichotomous variable. Body mass index is one measure of obesity (or Non-obesity). The BMI is universally expressed in $\left(\mathrm{kg} / \mathrm{m}^{2}\right) /\left(\mathrm{lb} / \mathrm{in}^{2}\right)$, resulting from mass in kilograms and height in meters. If pounds and inches are used, a conversion factor of 703 $\left(\mathrm{kg} / \mathrm{m}^{2}\right) /\left(\mathrm{lb} / \mathrm{in}^{2}\right)$ must be applied. When the term BMI is used informally, the units are usually omitted. The BMI is calculated by the following formula:

$$
\mathrm{BMI}=\frac{\text { Mass }_{\mathrm{kg}}}{\text { Height }_{\mathrm{m}}^{2}}=\frac{\text { Mass }_{\mathrm{lb}}}{\text { Height }_{\mathrm{in}}^{2}} \times 713
$$

BMI is classified as follows: a BMI from 18.5 up to 24.9 may indicate normal weight, a BMI lower than 18.5 suggests the person is underweight, a number from 25 up to 29.9 may indicate the person is overweight, and a number from 30 upwards suggests the person is obese.

\subsection{Independent Variables}

A great deal of explanatory variables is considered in our study. All the explanatory variables used in the analysis were not found directly from the BDHS data 
set. Again, we computed some new explanatory variable for convenience and transformed some original and computed variables that are suitable for the study. Some of the variables are coded as categorical and some are in dummy. The independent variables we used in this study are the Place of residence, Highest educational level, Religion, Sex of respondent, Wealth index, Current marital status, Ever had vaccination, Had diarrhea recently, Had fever in last two weeks, Had cough in last two weeks, Short, rapid breaths, Problem in the chest or blocked or running nose.

\section{Methodology}

In this research, both bivariate and multivariate techniques have used to perform the analysis of data. The Pearson Chi-Square test has used for bivariate analysis and the logistic regression has used for the multivariate analysis. Both techniques are described briefly below. In this study, statistical analysis has been carried out using IBM SPSS 21.

\subsection{Chi-Square Test}

A chi-square test, also written as $\chi^{2}$ test, is any statistical hypothesis test wherein the sampling distribution of the test statistic is chi-square distribution when the null hypothesis is true. A chi-squared test can be used to attempt rejection of the null hypothesis that the data are independent. It is also used to determine whether there is a significant difference between the expected frequencies and the observed frequencies in one or more categories. Recall that we can summarize two categorical variables within a two-way table, also called an $r \times c$ contingency table, where $r=$ number of rows, $c=$ number of columns. Our question of interest is "Are the two variables independent?" This question is set up using the following hypothesis statements:

Null Hypothesis: The two categorical variables are independent.

Alternative Hypothesis: The two categorical variables are dependent.

The chi-square test statistic is calculated by using the formula:

$$
\chi^{2}=\sum \frac{(O-E)^{2}}{E}=\sum \frac{O^{2}}{E}-n
$$

where, $O$ represents the observed frequency. $E$ is the expected frequency under the null hypothesis and computed by:

$$
E=\frac{\text { Row total } \times \text { Column total }}{\text { Sample size }}
$$

We will compare the value of the test statistic to the critical value of $\chi_{\alpha}^{2}$ with degree of freedom $=(r-1)(c-1)$, and reject the null hypothesis if $\chi^{2}>\chi_{\alpha}^{2}$.

\subsection{Logistic Regression}

Logistic regression is the appropriate regression analysis to conduct when the dependent variable is dichotomous (binary). Like all regression analyses, the 
logistic regression is a predictive analysis. Logistic regression is used to describe data and to explain the relationship between one dependent binary variable and one or more nominal, ordinal, interval or ratio-level independent variables. It enables us to determine which of our independent variables have statistically significant effect on the dependent variable of interest [3]. The goal of logistic regression is to find the best fitting (yet biologically reasonable) model to describe the relationship between the dichotomous characteristic of interest (dependent variable) and a set of independent (predictor or explanatory) variables. Logistic regression generates the coefficients (and its standard errors and significance levels) of a formula to predict a logit transformation of the probability of presence of the characteristic of interest:

$$
\operatorname{logit}(p)=b_{0}+b_{1} X_{1}+b_{2} X_{2}+b_{3} X_{3}+\cdots+b_{k} X_{k}
$$

where, $p$ is the probability of presence of the characteristic of interest. The logit transformation is defined as the logged odds:

$$
\text { odds }=\frac{p}{1-p}=\frac{\text { probability of presence of characteristics }}{\text { probalility of absence of characteristics }}
$$

And

$$
\operatorname{logit}(p)=\ln \left(\frac{p}{1-p}\right)
$$

We can also define odds of the dependent variable equaling a case (given some linear combination $x$ of the predictors) as follows:

$$
\text { odds }=e^{\beta_{0}+\beta_{1} x} \text { ooo }
$$

For a continuous independent variable, the odds ratio can be defined as:

$$
\mathrm{OR}=\frac{\operatorname{odds}(x+1)}{\operatorname{odds}(x)}=\frac{\left(\frac{F(x+1)}{1-F(x+1)}\right)}{\left(\frac{F(x)}{1-F(x)}\right)}=\frac{e^{\beta_{0}+\beta_{1}(x+1)}}{e^{\beta_{0}+\beta_{1} x}}=e^{\beta_{1}}
$$

This exponential relationship provides an interpretation for $\beta_{1}$ : The odds multiply by $e^{\beta_{1}}$ for every 1 -unit increase in $x$. The coefficients in the logistic regression model tell us how much the logit changes based on the values of the independent variables.

\section{Results and Discussion}

Table 1 shows the dependence of BMI classification (a measure of overweight and obesity) with all other explanatory variables. From the result of chi-square test we can see that among the explanatory variables type of place of residence, Highest educational level, Wealth index, Current marital status, Ever had vaccination, Had fever in last two weeks, Had cough in last two weeks, Short, rapid breaths and Problem in the chest or blocked or running nose have significant effect on dependent variable BMI classification. Only three variables 
Table 1. Significance in Chi-square test procedure.

\begin{tabular}{cccc}
\hline Variable & $\boldsymbol{\chi}^{2}$ value & df & $P$-Value \\
\hline Type of place of residence & 170.901 & 2 & 0.000 \\
Highest education level & 197.509 & 6 & 0.000 \\
Religion & 12.171 & 6 & 0.058 \\
Sex of respondent & 0.268 & 2 & 0.875 \\
Wealth index & 415.054 & 8 & 0.000 \\
Marital status & 67.694 & 2 & 0.000 \\
Ever had vaccination & 12.297 & 2 & 0.002 \\
Had diarrhea recently & 0.697 & 2 & 0.706 \\
Had fever in last two weeks & 12.915 & 2 & 0.002 \\
Had cough in last two weeks & 34.965 & 2 & 0.000 \\
Short, rapid breaths & 702.452 & 2 & 0.000 \\
Problem in the chest or blocked or running nose & 754.026 & 2 & 0.000 \\
\hline
\end{tabular}

namely Religion, Sex of respondent and had diarrhea recently have insignificant effect on BMI classification [4]-[20].

\section{Results and Discussion of Logistic Regression Analysis}

In this research, BMI classification is used as the explained (dependent) variable which has three categories: underweight, normal weight and overweight or obese. Therefore we have used multinomial logistic regression instead of binary logistic regression. The results of logistic regression are shown in Table 2. From Table 2, we can see that 9 variables appear as significant predictor among 12 independent variables. They are: type of place of residence, highest educational level, wealth index, current marital status, ever had vaccination, had fever in last two weeks, had cough in last two weeks, short, rapid breaths and problem in the chest or blocked or running nose. The results of logistic regression analysis present the estimate of the logistic regression coefficient ( $\beta$ ), S.E, Wald Test, degree of freedom, $p$-value, odds ratio and $95 \%$ confidence interval for the odds ratio. We can see that the value of odds ratio of the variable type of place of residence is 2.392. This value indicates that there is 2.392 times greater chance of being overweight or obese for urban population comparing with the rural population. The values of odds ratio of the variable highest educational level indicate that there are 0.412 times, 0.529 times and 0.661 times less chance of being overweight or obese for the category no education, primary level and secondary level respectively when higher education is considered as the reference category. Again wealth index is come out as a significant factor of BMI classification. Its odds ratios are $0.180,0.241,0.667$ and 0.518 which indicate that there are 0.180 times, 0.241 times, 0.667 times and 0.518 times less chance of being overweight or obese for the categories Poorest, Poorer, Middle class and Richer considering 
Table 2. Results of the logistic regression for the overweight or obese group in BMI classification*.

\begin{tabular}{|c|c|c|c|c|c|c|c|c|}
\hline \multirow[t]{2}{*}{ Variable } & \multirow[t]{2}{*}{$\beta$} & \multirow{2}{*}{$\begin{array}{c}\text { Standard } \\
\text { Error }\end{array}$} & \multirow[t]{2}{*}{ Wald test } & \multirow[t]{2}{*}{ Df } & \multirow[t]{2}{*}{$P$-value } & \multirow[t]{2}{*}{ Odds ratio } & \multicolumn{2}{|c|}{$\begin{array}{l}95 \% \mathrm{CI} \text { for } \\
\text { Odds ratio }\end{array}$} \\
\hline & & & & & & & Lower & Upper \\
\hline \multicolumn{9}{|c|}{ Type of Place of residence } \\
\hline Urban & 0.845 & 0.167 & 25.562 & 1 & 0.000 & 2.329 & 1.678 & 3.232 \\
\hline \multicolumn{9}{|l|}{ Rural (ref) } \\
\hline \multicolumn{9}{|c|}{ Highest educational level } \\
\hline No education & -0.886 & 0.325 & 7.411 & 1 & 0.006 & 0.412 & 0.218 & 0.780 \\
\hline Primary & -0.638 & 0.284 & 5.049 & 1 & 0.025 & 0.529 & 0.303 & 0.922 \\
\hline Secondary & -0.413 & 0.236 & 3.058 & 1 & 0.048 & 0.661 & 0.416 & 1.051 \\
\hline \multicolumn{9}{|l|}{ Higher (ref) } \\
\hline \multicolumn{9}{|c|}{ Religion } \\
\hline Islam & -2.604 & 1.549 & 2.827 & 1 & 0.093 & 0.074 & 0.004 & 1.539 \\
\hline Hinduism & -2.541 & 1.572 & 2.612 & 1 & 0.106 & 0.079 & 0.004 & 1.717 \\
\hline Buddhism & -1.622 & 1.880 & 0.744 & 1 & 0.388 & 0.198 & 0.005 & 7.865 \\
\hline \multicolumn{9}{|l|}{ Christianity (ref) } \\
\hline \multicolumn{9}{|c|}{ Sex of respondent } \\
\hline Male & 0.218 & 0.160 & 1.874 & 1 & 0.171 & 1.244 & 0.910 & 1.701 \\
\hline \multicolumn{9}{|l|}{ Female (ref) } \\
\hline \multicolumn{9}{|c|}{ Wealth index } \\
\hline Poorest & -1.714 & 0.324 & 28.082 & 1 & 0.000 & 0.180 & 0.096 & 0.340 \\
\hline Poorer & -1.424 & 0.291 & 3.921 & 1 & 0.000 & 0.241 & 0.136 & 0.426 \\
\hline Middle & -0.405 & 0.241 & 2.839 & 1 & 0.029 & 0.667 & 0.416 & 1.068 \\
\hline Richer & -0.659 & 0.223 & 8.697 & 1 & 0.003 & 0.518 & 0.334 & 0.802 \\
\hline \multicolumn{9}{|l|}{ Richest (ref) } \\
\hline \multicolumn{9}{|c|}{ Current marital status } \\
\hline Unmarried & -0.177 & 0.270 & 0.426 & 1 & 0.014 & 0.838 & 0.493 & 1.424 \\
\hline \multicolumn{9}{|l|}{ Married (ref) } \\
\hline \multicolumn{9}{|c|}{ Ever had vaccination } \\
\hline No & -0.036 & 0.257 & 0.019 & 1 & 0.042 & 1.128 & 0.835 & 1.697 \\
\hline \multicolumn{9}{|l|}{ Yes (ref) } \\
\hline \multicolumn{9}{|c|}{ Had diarrhea recently } \\
\hline No & -0.511 & 0.367 & 1.944 & 1 & 0.163 & 0.600 & 0.292 & 1.230 \\
\hline \multicolumn{9}{|l|}{ Yes (ref) } \\
\hline \multicolumn{9}{|c|}{ Had fever in last two weeks } \\
\hline no & 0.473 & 0.202 & 5.514 & 1 & 0.019 & 1.605 & 1.081 & 2.383 \\
\hline Yes (ref) & & & & & & & & \\
\hline
\end{tabular}




\begin{tabular}{|c|c|c|c|c|c|c|c|c|}
\hline \multicolumn{9}{|c|}{ Had cough in last two weeks } \\
\hline Yes & 2.337 & 0.273 & 73.512 & 1 & 0.000 & 10.348 & 6.066 & 17.655 \\
\hline no (ref) & & & & & & & & \\
\hline \multicolumn{9}{|c|}{ Short, rapid breaths } \\
\hline Yes & -4.805 & 0.269 & 319.736 & 1 & 0.000 & 2.008 & 1.805 & 2.412 \\
\hline \multicolumn{9}{|l|}{ no (ref) } \\
\hline \multicolumn{9}{|c|}{ Problem in the chest or blocked or running nose } \\
\hline Yes & 5.085 & 0.264 & 37.542 & 1 & 0.000 & 16.529 & 9.252 & 27.077 \\
\hline No (ref) & & & & & & & & \\
\hline
\end{tabular}

\footnotetext{
ref $=$ reference category, ${ }^{*}$ reference category of dependent variable (BMI classification) is normal weight.
}

Richest as the reference category. Current marital status is also a significant factor which odds ratio is 0.838 with $95 \%$ confidence interval $(0.493,1.424)$. It indicates that there is 0.838 times less chance of being overweight or obese for Unmarried group comparing with the married group. The odds ratio of the variable ever had vaccination indicates that there is 1.128 times greater chance of being overweight or obese for those who did not take vaccine considering those who took vaccine as the reference category. The variable had fever in last two weeks is come out as a significant factor of BMI classification with odds ratio 1.605 which means that there is 1.605 times greater chance of being overweight or obese for the people who had no fever comparing those who had fever in last two weeks. The value of odds ratio of the variable had cough in last two weeks is 10.348 and its $95 \%$ confidence interval is $(6.066,17.655)$. It indicates that there is 10.348 times greater chance of being overweight or obese for those who had cough considering those who had no cough in last two weeks as the reference category. The variable Short, rapid breaths are come out as a significant factor of BMI classification whose odds ratio is 2.008 and $95 \%$ confidence interval for odds ratio is $(1.805,2.412)$. This means that there is 2.008 times greater chance of being overweight or obese for the people who had short, rapid breaths considering the group of people who had no problem of short, rapid breath as the reference category. Finally, the variable Problem in the chest or blocked or running nose is also a significant factor of BMI classification. Its odds ratio is 16.529 and the $95 \%$ confidence interval for odds ratio is $(9.252,27.077)$ which indicates that there is 16.539 times greater chance of being overweight or obese for the group of people who had problem in the chest or blocked or running nose comparing with the group of people who had no problem in the chest or blocked or running nose.

\section{Summary and Conclusion}

The study shows that $10.77 \%$ male and $10.33 \%$ female people are overweight or obese and $11.87 \%$ live in urban area and the remaining $9.23 \%$ live in rural area 
among the overweight or obese people. From the research, it is also evident that among the overweight or obese people, there are $1.17 \%$ poorest, $1.98 \%$ are poorer, $3.81 \%$ are middle class, $4.98 \%$ are richer and the remaining $9.16 \%$ are richest. Based on the findings of our study, we can elucidate that obese people constitute a heterogeneous group in which the susceptibility for different disease differs substantially according to subsets of other biologic and socio-demographic circumstances. The results indicate a possibility to identify overweight and obese individuals with an increased risk of different diseases with global risk assessment. From this study, it is clear that overweight and obesity have significant impact on physical and psychological health status of people and leads to an increased risk of disease and mortality later on their life. Nowadays, it is becoming a serious public health concern all over the world. Based on the exploratory data, it is clearly shown that overweight and obese subjects have more unhealthy life years than normal weight subjects. This study provides evidence-based on large cohort studies, that there is a motivation for the development, implementation, and evaluation of new weight gain prevention programs. Recently, the World Health Report showed that healthy life expectancy increased forcefully during the last century in 193 countries. If the prevalence of obesity will further increase, it is reasonable to expect that healthy life expectancy may be adversely affected in recent future in societies with a high prevalence of obesity.

\section{Conflicts of Interest}

The authors declare no conflicts of interest regarding the publication of this paper.

\section{References}

[1] Flegal, K.M., Carroll, M.D., Kuczmarski, R.J. and Johnson, C.L. (1998) Overweight and Obesity in the United States: Prevalence and Trends, 1960-1994. International Journal of Obesity, 22, 39. https://doi.org/10.1038/sj.ijo.0800541

[2] National Institution of Population Research and Training, Mitra and Associates, ORC-Macro (2014) Bangladesh Demographic and Health Survey. Dhaka.

[3] Bursac, Z., Gauss, C.H., Williams, D.K. and Hosmer, D.W. (2008) Purposeful Selection of Variables in Logistic Regression. Source Code for Biology and Medicine, 3, 17. https://doi.org/10.1186/1751-0473-3-17

[4] Dietz, W.H. (1998) Health Consequences of Obesity in Youth: Childhood Predictors of Adult Disease. Pediatrics, 101, 518-525.

[5] Petry, K.U. (2014) HPV and Cervical Cancer. Scandinavian Journal of Clinical and Laboratory Investigation, 74, 59-62. https://doi.org/10.3109/00365513.2014.936683

[6] Javali, S.B. and Pandit, P.V. (2010) A Comparison of Ordinal Regression Models in an Analysis of Factors Associated with Periodontal Disease. Journal of Indian Society of Periodontology, 14, 155. https://doi.org/10.4103/0972-124X.75909

[7] Peeters, A., Barendregt, J.J., Willekens, F., Mackenbach, J.P., Al Mamun, A. and Bonneux, L. (2003) Obesity in Adulthood and Its Consequences for Life Expectancy: A Life-Table Analysis. Annals of Internal Medicine, 138, 24-32. https://doi.org/10.7326/0003-4819-138-1-200301070-00008 
[8] Ananth, C.V. and Kleinbaum, D.G. (1997) Regression Models for Ordinal Response: A Review of Methods and Application. International Journal of Epidemiology, 26, 1323-1333. https://doi.org/10.1093/ije/26.6.1323

[9] Norton, E.C., Cowart and Dowd, B.E. (2018) Log Odds and the Interpretation of Logit Models. Health Services Research, 53, 859-878. https://doi.org/10.1111/1475-6773.12712

[10] Pirmohamed, M., Breckenridge, A.M., Kitteringham, N.R. and Park, B.K. (1998) Adverse Drug Reactions. British Medical Journal, 316, 1295-1298. https://doi.org/10.1136/bmj.316.7140.1295

[11] Bärninghausen, T., Bloom, D., Canning, D. and O’Brien, J. (2008) Accounting for the Full Benefits of Childhood Vaccination in South Africa. South African Medical Journal, 98, 842-846.

[12] Harrison, J.A., Mullen, P.D. and Green, L.W. (1992) A Meta-Analysis of Studies of the Health Belief Model with Adults. Health Education Research, 7, 107-116. https://doi.org/10.1093/her/7.1.107

[13] Evans, S.J.W. (2000) Pharmacovigilance: A Science or Fielding Emergencies. Statistics in Medicine, 19, 3199-3209. https://doi.org/10.1002/1097-0258(20001215)19:23<3199::AID-SIM621>3.0.CO;2-Q

[14] Baah, E.M. (2019) Analysis of Adverse Events Reports Submitted to the Food and Drugs Administration of the United States of America (2007-2012). Asian Journal of Research in Medical and Pharmaceutical Sciences, 8, 1-17. https://doi.org/10.9734/ajrimps/2019/v8i1-230133

[15] Small, L., Tshifugula, N.P., Lita, H. and Tjiveze, K. (2012) Factors Associated with the Measles Immunisation Coverage in the Opuwo Health District, Kunene Region, Namibia. University of Namibia, Windhoek.

[16] National Center for Health Statistics (2017) Health, United States 2016; With Chartbook on Long-Term Trends in Health. Technical Report, US National Center for Health Statistics (HCHS), Hyattsville.

[17] Choe, E. and Min, D.B. (2006) Mechanisms and Factors for Edible Oil Oxidation. Comprehensive Reviews in Food Science and Food Safety, 5, 169-185. https://doi.org/10.1111/j.1541-4337.2006.00009.x

[18] German, J.B. (1999) Food Processing and Lipid Oxidation. Advances in Experimental Medicine and Biology, 459, 23-50. https://doi.org/10.1007/978-1-4615-4853-9_3

[19] Kanner, J. (2007) Dietary Advanced Lipid Oxidation End Products Are Risk Factors to Human Health. Molecular Nutrition \& Food Research, 51, 1094-1101. https://doi.org/10.1002/mnfr.200600303

[20] Csallany, A.S., Han, I., Shoeman, D.W., Chen, C. and Yuan, J. (2015) 4-Hydroxynonenal (HNE), a Toxic Aldehyde in French Fries from Fast Food Restaurants. Journal of the American Oil Chemists' Society, 92, 1413-1419.

https://doi.org/10.1007/s11746-015-2699-z 